\title{
Physics and its Application
}

\section{O.G. Folberth}

Chairman of the Advisory Committee on Applied

Physics and Physics in Industry.

Physics is a branch of human enterprise which has one of the most significant and radical influences on the development, structure and behaviour of the human race. It is impossible to imagine modern life without the great contributions to the improvement of human environment which are rooted in discoveries made in the evolution of physical science during the last centuries. Major sections of presentday industry are predominantly based on such understanding and mastery of physics. We can cite a few examples - all branches of the electrical industry from power-generation to electronics and computers; space-technology; production of materials from cast metals to compound-laminents; tools ranging from electron-beam drillers to ultra-precise clocks controlled by atomic motion.

Yet no "physical industry" exists which can really be given this title. Contrary to "chemical industry", which remains directly in close relation to basic chemistry, industrial branches which have evolved out of physics have tended to become more and more independent from their root. Their scientific and technological base is generally supported by newly created engineering disciplines such as nuclear power engineering or semiconductor engineering.

A result of this pattern is often an estrangement between "fundamental" physics and "applied" industry. Subsequently this can lead to the views that the work of the pure physicist is "esoteric" or "useless" (seen by the industrialist) or that the work of the industrialist is "second-rate" or "nonscientific" (seen by the pure physicist). This polarization has to be regarded as inhibiting the further progress of human enterprise. What would industry be without the physical discoveries on which they are based? And what would modern physics be without all the machinery provided by industry (e.g., particle accelerators, computers, and all kinds of scientific instruments)?

Unfortunately, the impact of physical discoveries on our environment is not only of a pleasant nature by far. Fall- out from nuclear explosions, excessive noise from supersonic jets, and the fast growing pollution of our natural surroundings are just a few instances of this. More and more physicists are turning their attention to these problems being stimulated by the vision that if nothing is done by those who might be the only ones capable of working out feasible solutions, the whole situation might soon get out of control.

The European Physical Society has recognized all these interdependency problems and has accepted as one of its chief objectives the responsibility of establishing an interface between physics and those branches of human activity where physics has been put to work, especially industry. On the initiative of the Executive Committee, an Advisory Committee for "Applied Physics and Physics in Industry" was established, providing thereby a forum in which all parties concerned are represented (See also R. Press: "Europhysics News" No. 7, p. 8). This committee met recently for the first time and gave itself the following "cahier de charge":

1. This Advisory Committee supports the Executive Committee in its task of promoting the application of physics in science, industry and all kinds of human activities.

2. Within the limits set by the Executive Committee, the Advisory Committee is free to initiate those activities appropriate to the aim of Article 1.

3. The Advisory Committee will encourage mutual contact between physicists working in different sections of science and industry through measures such as:

a) The introduction of applied physics aspects into appropriate EPS organized or sponsored conferences including, for example, the arranging of symposia and workshop discussions.

b) Endeavouring to secure adequate coverage of the application of physics in the Europhysics Journals and other publications of the EPS. c) Promoting the interchange of physicists particularly between the academic, government and industrial sectors, on a European basis.

d) Establishing contacts with organizations and activities concerned with the application of physics in Europe.

4. The Committee will consider ways of obtaining appropriate coverage of applied physics in the curricula of educational institutions of physics.

We hope to report in a forthcoming issue of Europhysics News the first concrete actions taken to further the cause outlined above.

An article on "Physics and Society" will appear in the next issue of Europhysics News. 